GROSS, Jacson; CARLOS, Paula Pinhal de. Da construção da sexualidade aos direitos LGBT: uma lenta conquista. Revista Eletrônica Direito e Política, Programa de Pós-Graduação Stricto Sensu em Ciência Jurídica da UNIVALI, Itajaí, v.10, n.2, $1^{0}$ quadrimestre de 2015. Disponível em: www.univali.br/direitoepolitica - ISSN 1980-7791.

\title{
DA CONSTRUÇÃO DA SEXUALIDADE AOS DIREITOS LGBT: UMA LENTA CONQUISTA
}

\author{
FROM CONSTRUCTION OF SEXUALITY TO LGBT RIGHTS: A SLOW \\ CONQUEST
}

Jacson Gross ${ }^{1}$

Paula Pinhal de Carlos ${ }^{2}$

SUMÁRIO: Introdução; 1 . Sexualidade, homossexualidades e heteronormatividade; 1.1 . O conceito de sexualidade e sua construção social; 2 . Homossexualidades e heteronormatividade; 2. Direitos LGBT; 2.1. Movimento LGBT brasileiro e demanda por direitos; 2.2. Direitos no âmbito civil; 2.3. Direitos no âmbito penal; Considerações Finais; Referências das Fontes Citadas.

RESUMO: Este artigo tem como objetivo principal tratar dos direitos de lésbicas, gays, bissexuais e transgêneros (LGBT). Parte-se dos estudos sobre sexualidade de Foucault, Weeks e Bozon, para entender a construção social da sexualidade, já que esses estudiosos demonstram que ela não é algo que pertence somente à natureza, devendo ser considerado o papel da cultura. É justamente a forma com que a sexualidade é construída em nossa sociedade, que dificulta a aceitação das pessoas LGBT na sociedade e incrementa o cerceamento de direitos a esses indivíduos. Por fim, trata-se aqui dos direitos LGBT nos âmbitos constitucional, civil e penal, pensando-se acerca da sua recepção e garantia pelo Direito Brasileiro.

Palavras-chave: Direitos LGBT, Sexualidade, Homossexualidades.

\footnotetext{
${ }^{1}$ Aluno do Mestrado em Direito e Sociedade do UNILASALLE/RS e bacharel em Direito pela mesma instituição. Canoas, Rio Grande do Sul, Brasil. E-mail: jacson.gross@gmail.com

2 Professora permanente do Mestrado em Direito e Sociedade e professora colaboradora do Mestrado em Memória Social e Bens Culturais do UNILASALLE/RS. Professora da graduação em Direito do UNIRITTER. Doutora em Ciências Humanas pela UFSC, mestra em Direito pela UNISINOS e bacharel em Ciências Jurídicas e Sociais pela mesma instituição. Canoas, Rio Grande do Sul, Brasil. E-mail: paulapinhal@hotmail.com
} 
GROSS, Jacson; CARLOS, Paula Pinhal de. Da construção da sexualidade aos direitos LGBT: uma lenta conquista. Revista Eletrônica Direito e Política, Programa de Pós-Graduação Stricto Sensu em Ciência Jurídica da UNIVALI, Itajaí, v.10, n.2, $1^{0}$ quadrimestre de 2015. Disponível em: www.univali.br/direitoepolitica - ISSN 1980-7791.

ABSTRACT: This article aims to deal with lesbian, gay, bisexual and transgender (LGBT) rights. It starts of studies on sexuality Foucault, Weeks and Bozon, to understand the social construction of sexuality, as these scholars show that it is not something that belongs only to the nature and should be considered the role of culture. It is precisely the way that sexuality is constructed in our society, which hinders the acceptance of LGBT people in society and increases the restriction of rights to such individuals. Finally, this is about LGBT rights in constitutional, civil and criminal areas, by thinking about the receipt and warranty by the Brazilian law.

Keywords: LGBT Rights, Sexuality, Homosexualities.

\section{INTRODUÇÃO}

Partindo-se da ideia da necessidade de aceitação da diversidade em sociedades complexas como a nossa, busca-se analisar o processo de busca por direitos das minorias sexuais. Os integrantes desses grupos encontram-se em situação de vulnerabilidade, na medida em que, ao romper com o modelo heteronormativo de orientação sexual e identidade de gênero, sofrem preconceito, discriminação e intolerância, materializada na homofobia, lesbofobia, bifobia e transfobia. Este artigo debruça-se sobre os conceitos sexualidade, heteronormatividade e sobre os direitos que indivíduos LGBT pleiteiam, a fim de trazer ao centro da discussão o conceito de construção social da sexualidade, concebendo-a como algo que não pertence somente à natureza, devendo ser considerado o papel da cultura. As movimentações por regulamentações dos direitos LGBT no Direito brasileiro, demonstram o aspecto combativo que esse tema tem tomado no país.

\section{SEXUALIDADE, HOMOSSEXUALIDADES E HETERONORMATIVIDADE}

\subsection{0 conceito de sexualidade e sua construção social}

A sexualidade humana é fruto de uma construção social. Assim sendo, não possui origem apenas na natureza, devendo ser considerado o papel que a sociedade possui sobre ela. Como construção social, a sexualidade não é aprendida isoladamente, sendo produto do momento histórico, da cultura e da 
GROSS, Jacson; CARLOS, Paula Pinhal de. Da construção da sexualidade aos direitos LGBT: uma lenta conquista. Revista Eletrônica Direito e Política, Programa de Pós-Graduação Stricto Sensu em Ciência Jurídica da UNIVALI, Itajaí, v.10, n.2, $1^{0}$ quadrimestre de 2015. Disponível em: www.univali.br/direitoepolitica - ISSN 1980-7791.

sociedade na qual é inserido o indivíduo. Pode-se dizer que a sexualidade é um fenômeno social e cultural. Abordando a ideia de construção social, Weeks ${ }^{3}$ conceitua sexualidade como sendo,

na verdade, uma 'construção social', uma invenção histórica, a qual, naturalmente, tem base nas possibilidades do corpo: o sentido e o peso que lhe atribuímos são, entretanto, modelados em situações sociais concretas. Isso tem profundas implicações para nossa compreensão do corpo, do sexo e da sexualidade.

Ainda tratando da construção social, da sexualidade Bozon ${ }^{4}$ explica que,

como construção social, a sexualidade humana implica, de maneira inevitável, a coordenação de uma atividade mental com uma atividade corporal, aprendidas ambas através da cultura. A sexualidade humana não é um dado da natureza. Construída socialmente pelo contexto cultural em que está inscrita, essa sexualidade extrai sua importância política daquilo que contribui, em retorno, para estruturar as relações culturais das quais depende, na medida em que "incorpora", e representa. (...) A sexualidade é uma esfera específica, mas não autônoma do comportamento humano, que compreende atos, relacionamentos, e significados (...). A sexualidade não se explica pela própria sexualidade, nem pela biologia. A sociologia da sexualidade é um trabalho infinito de contextualização social e cultural que visa estabelecer relações múltiplas, e por vezes, desconhecidas, dos fenômenos sexuais com os processos sociais, o que se pode chamar de construção social da sexualidade.

Para o filósofo francês Michel Foucault ${ }^{5}$, a sexualidade tomou função de controle dos indivíduos e das populações, uma separação entre normalidade e anormalidade, aceito e não aceito socialmente. Tornou-se instrumento de separação entre práticas sexuais bem educadas e as demais. O sexo bem educado ou normatizado era, e ainda o é hoje, aquele com práticas

\footnotetext{
${ }^{3}$ WEEKS, Jeffrey. O corpo e a sexualidade. Tradução Tomaz Tadeu da Silva. In: LOURO, Guacira Lopes. (Org.). O corpo educado: pedagogias da sexualidade. 2. ed. Belo Horizonte: Autêntica, 2000. p. 35-82. Tradução de: The body and sexuality. p. 40.

${ }^{4}$ BOZON, Michel. Sociologia da sexualidade. Tradução Maria de Lourdes Menezes. Rio de Janeiro: Ed. FGV, 2004. Tradução de: Sociologie de la sexualité. p. 14.

${ }^{5}$ FOUCAULT, Michel. História da Sexualidade. Tradução Maria Thereza da Costa Albuquerque, J. A. Guilhon Albuquerque. 13. ed. Rio de Janeiro: Edições Graal, 1999. v. 1: A vontade de saber. Tradução de: Histoire de la sexualité I: la volonté de savoir.
} 
GROSS, Jacson; CARLOS, Paula Pinhal de. Da construção da sexualidade aos direitos LGBT: uma lenta conquista. Revista Eletrônica Direito e Política, Programa de Pós-Graduação Stricto Sensu em Ciência Jurídica da UNIVALI, Itajaí, v.10, n.2, $1^{0}$ quadrimestre de 2015. Disponível em: www.univali.br/direitoepolitica - ISSN 1980-7791.

heterossexuais, monogâmicas, reprodutivas e chancelado pelo matrimônio. As demais práticas sexuais eram renegadas à marginalização. Exemplos de práticas marginalizadas, segundo o autor, seriam o homossexual, o onanista (define-se por onanista aquele que interrompe o ato sexual antes da ejaculação, ou ainda, aquele que pratica o ato da masturbação), e o casal malthusiano (McFarlane 6 denominou de casamento malthusiano o modelo de união conjugal que tem como premissas básicas o afeto, a amizade e o companheirismo entre os cônjuges e onde a procriação não é o objetivo principal do casamento). Ainda segundo Foucault ${ }^{7}$, o conceito de sexualidade que pertence à nossa história, nasceu como a justa medida de separação entre normalidade e anormalidade:

A sexualidade é o nome que se pode dar a um dispositivo histórico: não à realidade subterrânea que se aprende com dificuldade, mas à grande rede de superfície em que a estimulação dos corpos, a intensificação dos prazeres, a incitação ao discurso, a formação dos conhecimentos, o reforço dos controles e das resistências, encadeiam-se uns aos outros, segundo algumas grandes estratégias de saber e poder.

A identidade de gênero relaciona-se com as identificações histórico-sociais dos sujeitos, que se reconhecem como femininos ou masculinos, enquanto que a orientação sexual é a forma com que os indivíduos sentem e experimentam seus desejos $^{8}$. Segundo Borrillo ${ }^{9}$, as divisões de gênero e de desejo são identificações relacionadas com a reprodução da norma social, e não com a reprodução biológica da espécie. Portanto, representariam relações de poder, como já citado por Foucault anteriormente.

Nessas relações de poder são ditados os comportamentos a serem seguidos, as sexualidades concebidas como corretas e, por conseguinte, aceitas. Assim, nasce a heteronormatividade ditada socialmente como modelo a seguir.

\footnotetext{
6 McFARLANE, Alan. História do casamento e do amor: Inglaterra, 1300-1840. Tradução Paulo Neves. São Paulo: Companhia das Letras, 1990. Tradução de: Marriage and love in England: Modes of reproduction, $1300-1840$

7 FOUCAULT, Michel. História da Sexualidade.

8 LOURO, Guacira Lopes (Org.). Pedagogias da sexualidade. In: pedagogias da sexualidade. 2. ed. Belo Horizonte: Autêntica, 2000. p. 7-34.

O corpo educado:

9 BORRILlO, Daniel. A homofobia. In: Diniz, Debora; Lionço, Tatiana (Orgs.). Homofobia \& Educação: um desafio ao silêncio. Brasília: Letras Livres, 2009. p. 15-46.
} 
GROSS, Jacson; CARLOS, Paula Pinhal de. Da construção da sexualidade aos direitos LGBT: uma lenta conquista. Revista Eletrônica Direito e Política, Programa de Pós-Graduação Stricto Sensu em Ciência Jurídica da UNIVALI, Itajaí, v.10, n.2, $1^{0}$ quadrimestre de 2015. Disponível em: www.univali.br/direitoepolitica - ISSN 1980-7791.

Por heteronormatividade, entende-se a reprodução de práticas e códigos heterossexuais, sustentada pelo casamento monogâmico, amor romântico, fidelidade conjugal, constituição de família (esquema pai-mãe-filho (a) (s)). Na esteira das implicações da aludida palavra, tem-se o heterossexismo compulsório, sendo que, por esse último termo, entende-se o imperativo inquestionado e inquestionável por parte de todos os membros da sociedade com o intuito de reforçar ou dar legitimidade às práticas heterossexuais ${ }^{10}$.

Diante do exposto, é possível perceber que a sexualidade é um produto cultural, que os padrões são produzidos e reproduzidos, e que, portanto, são mutáveis. No entanto, a heteronormatividade na qual estamos imersos, faz com que sexualidades divergentes tendam a ser invisibilizadas e culpabilizadas, sem que percebamos ou questionemos esses processos.

\subsection{Homossexualidades e heteronormatividade}

O vocábulo heteronormatividade é formado pela conjunção de duas palavras "hetero" e "norma". O vocábulo "hetero" significa diferente e é antônimo de "homo", que significa igual. Já o vocábulo "norma" tem por significado preceito, regra, valor, modelo ${ }^{11}$. A partir desses termos, podemos definir heteronormatividade como modelo de relação com pessoa de sexo diferente do seu, a ser seguido como regra, ditado socialmente como modelo de valor. A heteronormatividade é entendida por Foster ${ }^{12}$ como

a reprodução de práticas e códigos heterossexuais, sustentada pelo casamento monogâmico, amor romântico, fidelidade conjugal, constituição de família (esquema pai-

\footnotetext{
10 FOSTER. David W. Consideraciones sobre el estudio de la heteronormatividade em la literatura latinoamericana. Letras: Literatura e Autoritarismo. Santa Maria, n. 22, jan./jun. 2001. p. 19.

11 PETRY, Analídia Rodolpho; MEYER, Dagmar Elisabeth Estermann. Transexualidade e heteronormatividade: algumas questões para a pesquisa. Textos \& Contextos. Porto Alegre, v. 10, n. 1, p. 193 - 198, jan./jul. 2011. p. 196.

POLITO, A. F.. Michaelis: moderno dicionário da língua portuguesa. 1. ed. São Paulo: Melhoramentos, 2004.

12 FOSTER. David W. Consideraciones sobre el estudio de la heteronormatividade em la literatura latinoamericana. Letras: Literatura e Autoritarismo. p. 19.
} 
GROSS, Jacson; CARLOS, Paula Pinhal de. Da construção da sexualidade aos direitos LGBT: uma lenta conquista. Revista Eletrônica Direito e Política, Programa de Pós-Graduação Stricto Sensu em Ciência Jurídica da UNIVALI, Itajaí, v.10, n.2, $1^{0}$ quadrimestre de 2015. Disponível em: www.univali.br/direitoepolitica - ISSN 1980-7791.

mãe-filho (a) (s)). Na esteira das implicações da aludida palavra, tem-se o heterossexismo compulsório, sendo que, por esse último termo, entende-se 0 imperativo inquestionado e inquestionável por parte de todos os membros da sociedade com o intuito de reforçar ou dar legitimidade às práticas heterossexuais.

As homossexualidades (adota-se 0 termo no homossexualidades pelo entendimento de que a presença do sufixo "ismo" na palavra homossexualismo ainda carregue caracteres de associação à doença/distúrbio mental) estiveram presentes no catálogo de Classificação Internacional de Doenças (CID) no rol de doenças mentais até 1990, quando foi retirado pela Organização Mundial da Saúde (OMS). O termo homossexualidade carrega em si, uma carga de significação, como Fry e Macrae ${ }^{13}$ descrevem:

O problema é que a homossexualidade é uma infinita variação sobre um mesmo tema: o das relações sexuais e afetivas entre pessoas do mesmo sexo. Assim, ela é uma coisa na Grécia Antiga, outra coisa na Europa do fim do século XIX, outra coisa ainda entre os índios Guaiqui do Paraguai. Com esse mesmo raciocínio, a homossexualidade pode ser uma coisa para um camponês do Mato Grosso, outra coisa para um candidato a governador do estado de São Paulo (...) tantas coisas quanto os diversos seguimentos sociais da sociedade brasileira contemporânea.

Fry e Macrae ${ }^{14}$ apontam também o quanto essas identificações pessoais variam de um lugar para outro, de um seguimento para outro. Trazendo alguns exemplos, mostram, que em determinado lugar, um homem que mantém relações sexuais com outro homem pode não se identificar como homossexual, ou um jovem rapaz, que mantém relação sexual com um senhor mais velho, por uns trocados, talvez também não se identifique como tal. Essa identificação ou não, seja ela uma identificação pessoal ou social, faz com que o termo homossexualidade torne-se quase de impossível condensação em um conceito sintético.

${ }^{13}$ FRY, Peter; MACRAE, Edward. O que é homossexualidade? 7. ed. São Paulo: Brasiliense, 1991. p. 7.

${ }^{14}$ FRY, Peter; MACRAE, Edward. O que é homossexualidade? p. 8-9. 
GROSS, Jacson; CARLOS, Paula Pinhal de. Da construção da sexualidade aos direitos LGBT: uma lenta conquista. Revista Eletrônica Direito e Política, Programa de Pós-Graduação Stricto Sensu em Ciência Jurídica da UNIVALI, Itajaí, v.10, n.2, $1^{0}$ quadrimestre de 2015. Disponível em: www.univali.br/direitoepolitica - ISSN 1980-7791.

\section{DIREITOS LGBT}

Em 2013, segundo pesquisa do Grupo Gay da Bahia (GGB) um homossexual era assassinado no Brasil a cada 28 horas (Pesquisa disponível no sitio do Grupo Gay da Bahia. Disponível em: <http://www.ggb.org.br/direitos.html.>), sendo que, metade dos assassinatos homofóbicos do mundo são cometidos somente no Brasil.

Agressões, torturas, discriminação em órgãos e por autoridades governamentais, discriminação econômica, contra a livre movimentação, privacidade e trabalho, discriminação familiar, escolar, científica e religiosa, difamação e discriminação na mídia, insulto e preconceito anti-homossexual, anti-lésbico e antitransgêneros são algumas formas comuns, e que muitas vezes passam despercebidas, de violência. A homofobia, lesbofobia, bifobia e transfobia têm múltiplas formas de expressão: desde piadas até representações estereotipadas. Pode-se dizer que é homofobia, lesbofobia, bifobia e transfobia a reação hostil às sexualidades desviantes da norma heterossexual. Hoje, o parlamento eleito no pleito de 2014, tem sido considerado o mais conservador do período pós-1964 (segundo dados do DIAP - Departamento Intersindical de Assessoria Parlamentar), podendo fazer com que as pautas LGBT corram o risco de não avançar. No entanto, passos foram dados nesta seara: alguns Estados estabelecem proibições de discriminação por motivos de orientação sexual, tais como o Mato Grosso, Sergipe, Piauí, e o Distrito Federal (em sua lei orgânica), uma vez que na Constituição Federal (CF) não há menção expressa proibindo a discriminação por motivo de orientação sexual.

Na Câmara dos Deputados Federal existem 20 proposições relacionadas à união ou ao casamento entre pessoas do mesmo sexo em pauta, sendo nove favoráveis, oito contrárias e três neutras ${ }^{15}$. Existe também, no âmbito penal, os projetos de proposição da criminalização da homofobia, englobando orientação sexual e identidade de gênero.

15 OLIVEIRA, Rosa Maria Rodrigues de. Direitos sexuais de LGBTTT no Brasil: jurisprudência, propostas legislativas e normatização federal. Brasília: Ministério da Justiça, 2013. 
GROSS, Jacson; CARLOS, Paula Pinhal de. Da construção da sexualidade aos direitos LGBT: uma lenta conquista. Revista Eletrônica Direito e Política, Programa de Pós-Graduação Stricto Sensu em Ciência Jurídica da UNIVALI, Itajaí, v.10, n.2, $1^{0}$ quadrimestre de 2015. Disponível em: www.univali.br/direitoepolitica - ISSN 1980-7791.

A Associação Brasileira de Lésbicas, Gays, Bissexuais, Travestis e Transexuais (ABGLT) lista em seu sítio (Disponível em: <http://www.abglt.org.br/port/78direitosnegados.php>) 78 direitos negados a casais homossexuais. A legislação brasileira ainda é bastante omissa no que tange aos direitos LGBT. Os direitos de cidadania do grupo LGBT são, de fato, deixados de lado pelo legislador, que se omite na hora da formulação de leis que defendam essas minorias, e isso ocorre - muitas vezes - por questões religiosas e morais, e que também podem trazer reflexos eleitorais frente a grupos conservadores da sociedade.

Ressalta-se que é importante que a legislação acompanhe as mudanças sociais que interferem na construção da sexualidade. É necessário considerar que a orientação sexual e a identidade de gênero não se revestem de caracteres de morbidez ou doença, motivo pelo qual tais direitos devem ser garantidos.

Serão analisados aqui direitos nos âmbitos civil e penal. Conforme Rios, Souza e Sponchiado ${ }^{16}$, na Constituição Federal (CF) não há proibição expressa de discriminação por motivo de orientação sexual. Logo, embora exista uma proibição genérica de não discriminação disposta nesse documento, não há menção expressa a questões relativas à orientação sexual e à identidade de gênero em nossa Constituição.

Ressalta-se, por fim, que, no tocante a leis federais há quatro diplomas legislativos que tratam o tema da discriminação:

a) a proibição de discriminação por motivo de "preferência sexual" (Lei no 9.612/1998, artigo 40, inciso IV): "não discriminação de raça, religião, sexo, preferências sexuais, convicções político-ideológicopartidárias e condição social nas relações comunitárias"17;

\footnotetext{
16 RIOS, Roger Raupp; SOUZA, Luiz Gustavo Oliveira de; SPONCHIADO, Tobias. Notícias de homofobia e proteção jurídica antidiscriminatória. In: DINIZ, Debora; OLIVEIRA, Rosana Medeiros de. (Orgs.). Notícias de homofobia no Brasil. Brasília: LetrasLivres, 2014. p. 164-174.

17 BRASIL. Lei no 9.612, de 19 de fevereiro de 1998. Institui o serviço de radiodifusão comunitária e dá outras providências. Disponível em: <http://www.planalto.gov.br/ccivil_03/leis/l9612.htm>. Acesso em: 19 dez. 2013.
} 
GROSS, Jacson; CARLOS, Paula Pinhal de. Da construção da sexualidade aos direitos LGBT: uma lenta conquista. Revista Eletrônica Direito e Política, Programa de Pós-Graduação Stricto Sensu em Ciência Jurídica da UNIVALI, Itajaí, v.10, n.2, $1^{0}$ quadrimestre de 2015. Disponível em: www.univali.br/direitoepolitica - ISSN 1980-7791.

b) a vedação de qualquer forma de discriminação em relação a pessoas portadoras de transtornos mentais, colocando a orientação sexual como critério proibido (Lei no 10.216/2001, artigo 10): "Os direitos e a proteção das pessoas acometidas de transtorno mental, de que trata esta Lei, são assegurados sem qualquer forma de discriminação quanto à raça, cor, sexo, orientação sexual, religião, opção política, nacionalidade, idade, família, recursos econômicos e ao grau de gravidade ou tempo de evolução de seu transtorno, ou qualquer outra"18; $^{18}$

c) a garantia de direitos fundamentais a toda mulher, independente de orientação sexual (Lei no 11.340/2006 - Lei Maria da Penha, artigo 20): "Toda mulher, independentemente de classe, raça, etnia, orientação sexual, renda, cultura, nível educacional, idade e religião, goza dos direitos fundamentais inerentes à pessoa humana, sendo-lhe asseguradas as oportunidades e facilidades para viver sem violência, preservar sua saúde física e mental e seu aperfeiçoamento moral, intelectual e social"19;

d) a proibição de anotações que incorporem informações não vinculadas à análise do risco de crédito (Lei no $12.414 / 2011$, artigo 30, inciso II), "informações sensíveis, assim consideradas aquelas pertinentes à origem social e étnica, à saúde, à informação genética, à orientação sexual e às convicções políticas, religiosas e filosóficas" ${ }^{20}$.

\footnotetext{
18 BRASIL. Lei no 10.216, de 6 de abril de 2001. Dispõe sobre a proteção e os direitos das pessoas portadoras de transtornos mentais e redireciona o modelo assistencial em saúde mental. Disponível em: <http://www.planalto.gov.br/ccivil_03/leis/leis_2001/l10216.htm>. Acesso em: 19 dez. 2013.

${ }^{19}$ BRASIL. Lei no 11.340, de 7 de agosto de 2006. Cria mecanismos para coibir a violência doméstica e familiar contra a mulher, nos termos do § 80 do art. 226 da Constituição Federal, da Convenção sobre a Eliminação de Todas as Formas de Discriminação contra as Mulheres e da Convenção Interamericana para Prevenir, Punir e Erradicar a Violência contra a Mulher; dispõe sobre a criação dos Juizados de Violência Doméstica e Familiar contra a Mulher; altera o Código de Processo Penal, o Código Penal e a Lei de Execução Penal; e dá outras providências. Disponível em: <http://www.planalto.gov.br/ccivil_03/_ato2004-2006/2006/lei//11340.htm>. Acesso em: 19 dez. 2013.
}

${ }^{20}$ BRASIL. Lei no 12.414, de 9 de junho de 2011. Disciplina a formação e consulta a bancos de dados com informações de adimplemento, de pessoas naturais ou de pessoas jurídicas, para 
GROSS, Jacson; CARLOS, Paula Pinhal de. Da construção da sexualidade aos direitos LGBT: uma lenta conquista. Revista Eletrônica Direito e Política, Programa de Pós-Graduação Stricto Sensu em Ciência Jurídica da UNIVALI, Itajaí, v.10, n.2, $1^{0}$ quadrimestre de 2015. Disponível em: www.univali.br/direitoepolitica - ISSN 1980-7791.

\subsection{Movimento LGBT brasileiro e demanda por direitos}

O LGBT brasileiro teve início com o que podemos chamar de Movimento Homossexual Brasileiro, o qual teve por alicerce o grupo Somos, primeiro grupo reconhecido como tendo uma proposta de defesa de demandas homossexuais, fundado em 1978, em São Paulo ${ }^{21}$. Já em 1979 foi organizado no Rio de Janeiro (RJ), o primeiro encontro de homossexuais militantes ${ }^{22}$ e, a partir desse, outros encontros aconteceram e outros grupos foram formados, espalhando o movimento pelo país.

$\mathrm{Na}$ primeira metade dos anos 1980, com o surgimento da Síndrome da Imunodeficiência Adquirida (AIDS), tida inicialmente como "peste gay" ou "câncer gay", houve redução dos grupos, bem como uma mudança de foto na atuação desses, que passaram a se preocupar com a luta contra a epidemia. Essa reação é tida como uma das primeiras respostas da sociedade civil brasileira a epidemia de $\operatorname{AIDS}^{23}$.

A partir de 1992, a quantidade de grupos nos encontros nacionais começa a crescer novamente ${ }^{24}$, diversificando os formatos institucionais e propostas de atuação. No final da década de 1990, surge o Grupo CORSA. Esse é um momento em que o grupo Somos cresce, tendo a adesão inclusive de mulheres. Destaca-se também a formação de novos grupos, como o Eros e o Libertos.

Essas instituições, Organizações Não Governamentais (ONGs), fundações, entre outras nomenclaturas, têm papel fundamental na sociedade brasileira, uma vez que representam o grupo LGBT frente ao Estado para atingir seus direitos que, em sua maioria, são alcançados somente na esfera judicial.

formação de histórico de crédito. Disponível em: <http://www.planalto.gov.br/ccivil_03/_Ato20112014/2011/Lei/L12414.htm >. Acesso em: 19 dez. 2013.

${ }^{21}$ FACCHINI, Regina. Sopa de letrinhas?: movimento homossexual e produção de identidades coletivas nos anos 90. Rio de Janeiro: Garamond, 2005. p. 66.

22 FACCHINI, Regina. Sopa de letrinhas?: movimento homossexual e produção de identidades coletivas nos anos 90. p. 67.

${ }^{23}$ FACCHINI, Regina. Sopa de letrinhas?: movimento homossexual e produção de identidades coletivas nos anos 90. p. 73.

${ }^{24}$ FACCHINI, Regina. Sopa de letrinhas?: movimento homossexual e produção de identidades coletivas nos anos 90. p. 87 e 101. 
GROSS, Jacson; CARLOS, Paula Pinhal de. Da construção da sexualidade aos direitos LGBT: uma lenta conquista. Revista Eletrônica Direito e Política, Programa de Pós-Graduação Stricto Sensu em Ciência Jurídica da UNIVALI, Itajaí, v.10, n.2, 10 quadrimestre de 2015. Disponível em: www.univali.br/direitoepolitica - ISSN 1980-7791.

\subsection{Direitos no âmbito civil}

Em cinco de maio de 2011, o Supremo Tribunal Federal (STF) julgou a Ação Direta de Inconstitucionalidade (ADI) no 4.277 e a Arguição de Descumprimento de Preceito Fundamental (ADPF) no 132, reconhecendo a união estável entre casais do mesmo sexo. Excluiu, assim, qualquer significado do artigo 1.723 do Código Civil (CC) que impeça o reconhecimento da união das pessoas do mesmo sexo como entidade familiar. Reza o citado artigo que "é reconhecida como entidade familiar a união estável entre o homem e a mulher, configurada na convivência pública, contínua e duradoura e estabelecida com o objetivo de constituição de família". Dessa maneira, conferiu interpretação a esse dispositivo à luz da $\mathrm{CF}$, em seu artigo $3^{\circ}$, inciso IV, que veda qualquer discriminação em virtude de sexo, raça ou cor. O relator da ação, Ministro Carlos Ayres Britto, em seu voto, resume: "A nossa Magna Carta não emprestou ao substantivo família nenhum significado ortodoxo". E acrescenta: "Não existe família de segunda classe ou família mais ou menos"25.

\subsection{Direitos no âmbito penal}

Em matéria penal destacam-se os projetos de lei no $2.773 / 2000$, de autoria do Deputado Alceste Almeida (PTB-RR) e 6.871/2006, de autoria da deputada Laura Carneiro (PFL/PTB-RJ - o Partido da Frente Liberal - PFL, foi extinto em 2007), os quais excluem do Código Penal Militar o crime de "pederastia", bem como diversos projetos de lei que criminalizam condutas homofóbicas, as quais, em última análise, são discriminações por motivo de orientação sexual, contrárias ao ordenamento jurídico ${ }^{26}$. Há também a proposição da criminalização da

\footnotetext{
${ }^{25}$ BRASIL. Supremo Tribunal Federal. Argüição de descumprimento de preceito fundamental no 132/RJ. Relator: Ministro Ayres Brito. Brasília, 05 de maio de 2011. Disponível em: $<$ http://redir.stf.jus.br/paginadorpub/paginador.jsp?docTP=AC\&docID=628633>. Acesso em: 02 set. 2013. p. 24 e 29.

${ }^{26}$ BRASIL. Câmara dos Deputados. Projeto de lei no 2.773/2000. Altera a redação do art. 235, do Código Penal Militar, excluindo do texto o crime de pederastia. Disponível em: <http://www.camara.gov.br/proposicoesWeb/fichadetramitacao?idProposicao=18609>. Acesso em: 30 jul. 2014.
} 
GROSS, Jacson; CARLOS, Paula Pinhal de. Da construção da sexualidade aos direitos LGBT: uma lenta conquista. Revista Eletrônica Direito e Política, Programa de Pós-Graduação Stricto Sensu em Ciência Jurídica da UNIVALI, Itajaí, v.10, n.2, $1^{0}$ quadrimestre de 2015. Disponível em: www.univali.br/direitoepolitica - ISSN 1980-7791.

homofobia, que tenta englobar a orientação sexual e identidade de gênero, que desde 2001 tramita nas casas legislativas, inicialmente na Câmara dos Deputados, e agora no Senado, sob o registro Projeto de Lei da Câmara (PLC) 122/2006. Esse projeto foi aprovado com substitutivos e encontra-se atualmente apensado ao projeto de reforma do Código Penal, impossibilitando sua tramitação. No Senado Federal também encontra-se o Projeto de Lei do Senado (PLS) no 457/2011, de autoria do Senador Pedro Taques (PDT-MT), o qual "aumenta a pena dos crimes contra a honra, previstos nos arts. no 138, 139 e 140 , caput e $\S 2^{\circ}$; altera a redação do $\S 3^{\circ}$ do art. 140 , para incluir a orientação sexual e identidade de gênero como elementos para injúria qualificada"27.

\section{CONSIDERAÇÕES FINAIS}

A legislação brasileira ainda é omissa no que tange a direitos LGBT. Os direitos de cidadania do grupo LGBT são, de fato, deixados de lado pelo legislador, não compactua com a formulação de leis que defendam essas minorias, por questões religiosas, morais, e que podem trazer reflexos eleitorais frente a grupos conservadores da sociedade. Ressaltamos que é importante que a legislação acompanhe as mudanças sociais e comportamentais que interferem, como já referido, na construção da sexualidade. É necessário considerar que a orientação sexual e a identidade de gênero não se revestem de caracteres de morbidez ou doença, motivo pelo qual tais direitos devem ser garantidos. Por fim, acreditamos que a garantia de direitos à essa minoria é também imprescindível à redução da violência contra indivíduos LGBT.

BRASIL. Câmara dos Deputados. Projeto de lei no 6.871/2006. Altera a redação do art. 235 do Código Penal Militar, excluindo do nome jurídico o termo "pederastia" e do texto a expressão "homossexual ou não" e acrescentando parágrafo único, para excepcionar a incidência. Disponível em: $\quad<$ http://www.camara.gov.br/proposicoesWeb/fichadetramitacao?idProposicao=319817>. Acesso em: 30 jul. 2014.

27 OLIVEIRA, Rosa Maria Rodrigues de. Direitos sexuais de LGBTTT no Brasil: jurisprudência, propostas legislativas e normatização federal. p. 102. 
GROSS, Jacson; CARLOS, Paula Pinhal de. Da construção da sexualidade aos direitos LGBT: uma lenta conquista. Revista Eletrônica Direito e Política, Programa de Pós-Graduação Stricto Sensu em Ciência Jurídica da UNIVALI, Itajaí, v.10, n.2, $1^{0}$ quadrimestre de 2015. Disponível em: www.univali.br/direitoepolitica - ISSN 1980-7791.

\section{REFERÊNCIAS DAS FONTES CITADAS}

BORRILLO, Daniel. A homofobia. In: DINIZ, Debora; LIONÇO, Tatiana (Orgs.). Homofobia \& Educação: um desafio ao silêncio. Brasília: Letras Livres, 2009. p. $15-46$.

BOZON, Michel. Sociologia da sexualidade. Tradução Maria de Lourdes Menezes. Rio de Janeiro: Ed. FGV, 2004. Tradução de: Sociologie de la sexualité.

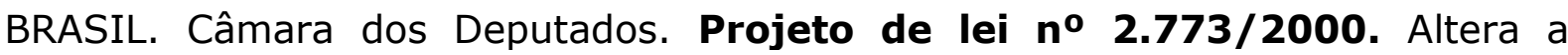
redação do art. 235, do Código Penal Militar, excluindo do texto o crime de pederastia. Disponível em: <http://www.camara.gov.br/proposicoesWeb/fichadetramitacao?idProposicao=1 8609>. Acesso em: 30 jul. 2014.

Câmara dos Deputados. Projeto de lei no 6.871/2006. Altera a redação do art. 235 do Código Penal Militar, excluindo do nome jurídico o termo "pederastia" e do texto a expressão "homossexual ou não" e acrescentando parágrafo único, para excepcionar a incidência. Disponível em: <http://www.camara.gov.br/proposicoesWeb/fichadetramitacao?idProposicao=3 19817>. Acesso em: 30 jul. 2014.

BRASIL. Constituição (1988). Constituição da República Federativa do Brasil
de
$\begin{aligned} & \mathbf{1 9 8 8} . \\ & \text { <http://www.planalto.gov.br/ccivil 03/constituicao/constituicao.htm>. }\end{aligned}$ em: 02 set. 2013.

Lei no 9.612, de 19 de fevereiro de 1998. Institui o serviço de radiodifusão comunitária e dá outras providências. Disponível em: <http://www.planalto.gov.br/ccivil_03/leis/I9612.htm>. Acesso em: 19 dez. 2013.

Lei no 10.216, de 6 de abril de 2001. Dispõe sobre a proteção e os direitos das pessoas portadoras de transtornos mentais e redireciona o modelo assistencial em saúde mental. Disponível em: <http://www.planalto.gov.br/ccivil_03/leis/leis_2001//10216.htm>. Acesso em: 19 dez. 2013.

Lei no 11.340, de 7 de agosto de 2006. Cria mecanismos para coibir a violência doméstica e familiar contra a mulher, nos termos do § 80 do art. 226 da Constituição Federal, da Convenção sobre a Eliminação de Todas as Formas de Discriminação contra as Mulheres e da Convenção Interamericana para Prevenir, Punir e Erradicar a Violência contra a Mulher; dispõe sobre a criação dos Juizados de Violência Doméstica e Familiar contra a Mulher; altera o Código de Processo Penal, o Código Penal e a Lei de Execução Penal; e dá outras providências. Disponível em: <http://www.planalto.gov.br/ccivil_03/_ato20042006/2006/lei/l11340.htm>. Acesso em: 19 dez. 2013.

Lei no 12.414, de 9 de junho de 2011. Disciplina a formação e consulta a bancos de dados com informações de adimplemento, de pessoas 
GROSS, Jacson; CARLOS, Paula Pinhal de. Da construção da sexualidade aos direitos LGBT: uma lenta conquista. Revista Eletrônica Direito e Política, Programa de Pós-Graduação Stricto Sensu em Ciência Jurídica da UNIVALI, Itajaí, v.10, n.2, $1^{0}$ quadrimestre de 2015. Disponível em: www.univali.br/direitoepolitica - ISSN 1980-7791.

naturais ou de pessoas jurídicas, para formação de histórico de crédito. Disponível em: <http://www.planalto.gov.br/ccivil_03/_Ato20112014/2011/Lei/L12414.htm>. Acesso em: 19 dez. 2013.

Supremo Tribunal Federal. Ação direta de inconstitucionalidade no 4.277/DF. Relator: Ministro Ayres Brito. Brasília, 05 de maio de 2011. Disponível em: <http://www.stf.jus.br/portal/geral/verPdfPaginado.asp?id $=400547 \&$ tipo $=$ TP\&de scricao=ADI\%2F4277>. Acesso em: 02 set. 2013.

Supremo Tribunal Federal. Argüição de descumprimento de preceito fundamental no 132/RJ. Relator: Ministro Ayres Brito. Brasília, 05 de maio de 2011. Disponível em: <http://redir.stf.jus.br/paginadorpub/paginador.jsp?docTP=AC\&docID=628633> . Acesso em: 02 set. 2013.

FACCHINI, Regina. Sopa de letrinhas?: movimento homossexual e produção de identidades coletivas nos anos 90. Rio de Janeiro: Garamond, 2005.

FOSTER. David W. Consideraciones sobre el estudio de la heteronormatividade em la literatura latinoamericana. Letras: Literatura e Autoritarismo. Santa Maria, n. 22, jan./jun. 2001.

FOUCAULT, Michel. História da Sexualidade. Tradução Maria Thereza da Costa Albuquerque, J. A. Guilhon Albuquerque. 13. ed. Rio de Janeiro: Edições Graal, 1999. v. 1: A vontade de saber. Tradução de: Histoire de la sexualité I: la volonté de savoir.

FRY, Peter; MACRAE, Edward. O que é homossexualidade? 7. ed. São Paulo: Brasiliense, 1991.

LOURO, Guacira Lopes (Org.). Pedagogias da sexualidade. In: O corpo educado: pedagogias da sexualidade. 2. ed. Belo Horizonte: Autêntica, 2000. p. 7-34.

McFARLANE, Alan. História do casamento e do amor: Inglaterra, 1300-1840. Tradução Paulo Neves. São Paulo: Companhia das Letras, 1990. Tradução de: Marriage and love in England: Modes of reproduction, 1300-1840.

OLIVEIRA, Rosa Maria Rodrigues de. Direitos sexuais de LGBTTT no Brasil:

jurisprudência, propostas legislativas e normatização federal. Brasília:

Ministério da Justiça, 2013.

PETRY, Analídia Rodolpho; MEYER, Dagmar Elisabeth Estermann. Transexualidade e heteronormatividade: algumas questões para a pesquisa. Textos \& Contextos. Porto Alegre, v. 10, n. 1, p. 193 - 198, jan./jul. 2011. 
GROSS, Jacson; CARLOS, Paula Pinhal de. Da construção da sexualidade aos direitos LGBT: uma lenta conquista. Revista Eletrônica Direito e Política, Programa de Pós-Graduação Stricto Sensu em Ciência Jurídica da UNIVALI, Itajaí, v.10, n.2, $1^{0}$ quadrimestre de 2015. Disponível em: www.univali.br/direitoepolitica - ISSN 1980-7791.

POLITO, A. F.. Michaelis: moderno dicionário da língua portuguesa. 1. ed. São Paulo: Melhoramentos, 2004.

RIOS, Roger Raupp; SOUZA, Luiz Gustavo Oliveira de; SPONCHIADO, Tobias. Notícias de homofobia e proteção jurídica antidiscriminatória. In: DINIZ, Debora; OLIVEIRA, Rosana Medeiros de. (Orgs.). Notícias de homofobia no Brasil. Brasília: LetrasLivres, 2014. p. 159-190.

WEEKS, Jeffrey. O corpo e a sexualidade. Tradução Tomaz Tadeu da Silva. In: LOURO, Guacira Lopes. (Org.). O corpo educado: pedagogias da sexualidade. 2. ed. Belo Horizonte: Autêntica, 2000. p. 35-82. Tradução de: The body and sexuality.

Submetido em: Março/2015

Aprovado em: Abril/2015 